\title{
BMJ Open Assessment of COVID-19-related awareness, knowledge, prevention practices and challenges faced by truck drivers in major transport cities of India: a cross-sectional survey
}

\author{
Ishaana Sood (D) , ${ }^{1}$ Anand Chinnakaran, ${ }^{2}$ Atanu Majumdar, ${ }^{3}$ \\ Shalinder Sabherwal (D) ${ }^{1}$
}

To cite: Sood I, Chinnakaran A, Majumdar A, et al. Assessment of COVID-19-related awareness, knowledge, prevention practices and challenges faced by truck drivers in major transport cities of India: a crosssectional survey. BMJ Open 2022;12:e052543. doi:10.1136/ bmjopen-2021-052543

- Prepublication history for this paper is available online. To view these files, please visit the journal online (http://dx.doi. org/10.1136/bmjopen-2021 052543).

Received 19 April 2021 Accepted 26 January 2022

\section{Check for updates}

(c) Author(s) (or their employer(s)) 2022. Re-use permitted under CC BY-NC. No commercial re-use. See rights and permissions. Published by BMJ.

${ }^{1}$ Department of Community Ophthalmology and Public Health Research, Dr Shroff's Charity Eye Hospital Delhi, New Delhi, Delhi, India

${ }^{2}$ Department of Community Outreach and Public Health Research, Dr Shroff's Charity Eye Hospital Delhi, New Delhi, Delhi, India

${ }^{3}$ Bio-statistician, Dr Shroff's Charity Eye Hospital Delhi, New Delhi, Delhi, India

Correspondence to Dr Shalinder Sabherwal; Shalinder.sabherwal@sceh.net

\section{ABSTRACT}

Objectives To assess COVID-19-related awareness and knowledge among truck drivers across India and report prevention practices followed, and challenges faced, by them during the COVID-19 lockdown.

Design Cross-sectional study.

Setting Delhi, Kanpur, Kolkata and Bangalore from July to September 2020.

Participants Data were collected in Hindi using a structured questionnaire via telephonic interviews. Minimum 200 drivers were included from each location. Outcome measures Sociodemographic profile, awareness regarding COVID-19, knowledge regarding infection sources, disease spread and vulnerable populations, prevention practices followed and challenges faced. Information sources were also assessed.

Results Fisher's exact test and Analysis of variance (ANOVA) test were used to check for significant differences across proportions. $P$ value less than 0.05 was considered significant. Overall, 1246 drivers were included, with $72 \%$ response rate. Of 1246 drivers, $65 \%$ were $30-50$ years of age. A majority correctly answered knowledge questions regarding communicability (95\%) and fatality (66\%). Fifty per cent drivers were aware of treatability of the disease, while only $43 \%$ and $24 \%$ correctly reported all signs and symptoms and routes of transmission, respectively. No driver was aware of all high-risk populations. Overall Knowledge Score is significantly associated with region. Mobile phones were the primary source of information across all regions. Over two-third drivers follow all prevention practices regularly, which differed significantly across regions. Following standard prevention practices was positively correlated with higher knowledge scores and was significantly correlated with mask use. Worry about the disease was common. Less than $40 \%$ drivers received full payment for work during this period, while $25 \%$ drivers were unable to return home due to the pandemic. Seven per cent and $26 \%$ drivers had either limited or no access to food and health services, respectively.

Conclusions Awareness activities and employer provisioned social security/health insurance might safeguard this vulnerable population till the pandemic fully abates as well as in similar situations in the future.

\section{Strengths and limitations of this study}

- The survey being administered to truck drivers across the country adds to the generalisability of the results.

- The survey was done soon after national lockdown, thus limiting the recall bias.

- As data collection was done through telephonic interview, only those drivers could be included who had accessed services of the programme at least once and shared contact details.

- The safety practices being followed were selfreported as observations were not feasible.

\section{INTRODUCTION}

In January 2020, the rapid spread of the SARS-CoV-2 virus, colloquially termed as the COVID-19 virus, led to the WHO declaring of a public health emergency of international concern. ${ }^{1}$ Globally, the response to counter the growing number of cases, slow infection rates and prevent overcrowding of the health systems, was to implement shelter in place policies and close borders, both international and state. ${ }^{2-5}$

As of 2007, 5-6million truck drivers, comprising a large part of the Indian transport industry, ${ }^{6}$ contribute significantly to the 1.42 trillion (Indian National Rupees) industry. ${ }^{7}$ Although the lockdown and subsequent restrictions have been reported as effective policy measures in terms of preventing and delaying the spread of the virus, ${ }^{8}$ studies of patients seeking care during the pandemic exemplify the need to increase patient awareness regarding the epidemic. ${ }^{910}$ For truck drivers rendered vulnerable to disease $\mathrm{e}^{11-13}$ due to their iterant lifestyle, ${ }^{14}{ }^{15}$ barriers to healthcare access reported on previously, ${ }^{16}$ intensify in such situations, despite efforts to 
close the loop of care provisioned. ${ }^{14} 17$ Thus, the nationwide lockdown implemented in India on the 24 March 2020 and had deep ramifications for this vulnerable population, both due to the mobile nature of their jobs and the high risk of infection due to existing comorbidities. ${ }^{11-131819}$ The lockdown was lifted starting 8 June 2020.

Our organisation, in collaboration with an auto-motive manufacturing partner, conceptualised the Driver Care Programme (DCP) in 2016. The DCP was implemented across the national capital region initially and then expanded across north India. Through the programme, truck drivers are provided accessible and affordable eyecare services at the transport areas frequented by them. During the lockdown, usual services provisioned through the DCP were suspended, although truck drivers around the national capital region were offered a hygiene kit (10 masks, one sanitizer and one hand wash) from April to June 2020. While services were resumed as per normal from July 2020, the numbers of drivers at the camp sites were low due to varied lifting of restrictions across zones.

Considerable literature has been published regarding the knowledge and awareness of COVID-19 and prevention practices across populations, ${ }^{20-34}$ highlighting the need for the same. However, among the nomadic truck driver population, knowledge, awareness and prevention practice, assessments have been limited to other health conditions. ${ }^{35-39}$ While the Centre for Disease Control in the USA has shared some policies for long-haul truck drivers, ${ }^{40}$ these are not always applicable or available for their Indian counterparts.

Therefore, in an attempt to bridge this gap in the literature, this study assesses the COVID-19-related awareness, knowledge and prevention practice among Indian truck drivers enrolled in the DCP. It also reviews the challenges faced by then during the lockdown period implemented to curb the pandemic. These findings would help to assess if there is a need to develop awareness activities for truck drivers regarding the effects of the pandemic as well as assist the design of implementation strategies for healthcare delivery to this target population through the DCP, in the aftermath of the pandemic and the lockdown.

\section{METHODS}

\section{Study design, study period and setting}

This cross-sectional telephonic survey was conducted for drivers accessing DCP services at the four major transport hub cities of the country; Delhi, Kanpur, Kolkata and Bangalore, from July to September 2020, after the lockdown period.

\section{Inclusion-exclusion criteria}

All truck drivers registered with, and accessing services through, the DCP in their respective cities, 1 month prior to the national lockdown were included in the survey. The study did not include drivers to whom hygiene kits had been distributed through the DCP during the lockdown. Truck drivers unwilling to give their consent or not contactable via telephone did not participate.

\section{Sample size and sampling}

The statistically valid minimum required sample size was 800 , that is, 200 from each location. The statistical parameters for calculating the sample size were level of confidence $(95 \%)$, one side length of CI 0.10 (for estimating proportions) and design effect $=2$. The same sample size was also sufficient for statistical testing of significance of a difference of $20 \%$ between two population proportions with $5 \%$ type-I error and $80 \%$ power.

A predecided methodology and order of sample selection were put in place and used to reduce selection bias. As a protocol, calls were made starting from the last truck drivers who registered to the DCP, due to greater probability of their contact details remaining unchanged. Calls were made in that order till the calculated sample size was achieved.

\section{Informed consent}

Verbal informed consent was embedded at the start of the structured questionnaire and was taken from all study participants. They were assured that their responses would be anonymised and kept confidential from the fleet owners as well as the hospital staff. They were also told that they could leave the interview at any time, not answer questions they felt uncomfortable with and that services offered to them through the DCP would not be affected by their decision to withdraw from the study.

\section{Data collection and pilot}

Data were collected via a telephonic survey conducted using a structured questionnaire. The questionnaire was developed in English and then translated into the local language (Hindi), in which it was administered by a team of four staff members, one from each location. However, the questionnaire was not backtranslated into English. Each interviewer had a Bachelors degree at the very minimum and was trained to properly administer the questionnaire, especially in terms of correctly conveying the question without using leading language. Project manager supervised the data collection and randomly repeated one interview conducted by each interviewee, to ensure data quality.

The questionnaire was piloted on 40 truck drivers for language clarity, time and validation. Between the pilot and the final questionnaire, three demographic questions were removed. The questions pertaining to the hometown and driving districts of the driver were removed as the information they provided repeated that available through the region of the interviewer. The question pertaining to the size of the vehicles (number of wheels) driven by the truck drivers was also removed as most of the drivers in the pilot were flexible and reported driving vehicles of all sizes. Finally, the responses to the question pertaining to the education level of the truck drivers were decreased to just 'literate' and 'illiterate' after discussion 
with the statistician, to reduce the length of the interview. Pilot data were not included in the study.

\section{Variables}

Information was collected about the sociodemographic profile of participants, their awareness regarding the disease including the sources of information they frequent, their knowledge regarding the sources of infection, spread of the disease and high-risk populations as well as their use of recommended prevention practices. Furthermore, challenges faced by them during the multiple lockdown periods in terms of essential needs and financial constraints were also examined.

\section{Statistical analysis}

Most of the variables explored through the study were dichotomous and, hence, summarised by percentage, estimating the population proportions. Suitable statistical tests (Fisher's exact test for categorical variable and Analysis of variance (ANOVA) test for continuous variables) were performed to check the significance of difference across the age groups. A p value of less than 0.05 was considered significant. We computed a new variable Knowledge Score to reflect the overall knowledge of individual truck drivers about COVID-19. A correct and complete answer to each knowledge question contributes one to the Knowledge Score variable. The score was then converted into a percentage and treated as a continuous variable. The data were analysed using R V.4.03

\section{Patient and public involvement}

Stakeholders were involved in the development of the questionnaire as a pilot was conducted with 40 truck drivers and the questionnaire was then modified on the basis of their responses, prior to finalisation for use in the study. Moreover, fleet owners were made aware of the process, without disclosing the identity or individual responses of the participants. Furthermore, results will be disseminated to fleet owners by involving them in awareness sessions arranged for the truck drivers to ensure a large audience and greater impact. Information, education and communication material will also be developed to be distributed to truck drivers at these sessions and while they access services through the DCP. Furthermore, results will be disseminated to the public, planners of similar programmes and policy makers through their publication.

\section{RESULTS}

\section{Response rate and demographic details}

The investigators for the study tried to connect with 1740 truck drivers who met the inclusion criteria. The contact numbers were incomplete for 10 . From the remaining 1730 , the call did not connect or got disconnected before the interview started for $376 ; 108$ did not agree to participate. The remaining 1255 drivers agreed to participate in the survey, but nine discontinued after answering only
Table 1 Demographic details of participants (original)

\begin{tabular}{lll}
\hline Category & Frequency (\%) & P value \\
\hline Age Category (years) & & \\
Below 30 & $217(17.42)$ & $<0.001^{*}$ \\
30-50 & $813(65.25)$ & \\
Above 50 & $216(17.34)$ & \\
Total & 1246 & \\
Driving Experience (years) & & \\
\hline Below 2years & $59(4.74)$ & $<0.001^{*}$ \\
2-10years & $320(25.68)$ & \\
Over 10 & $867(69.58)$ & \\
Total & 1246 & \\
Education Level & & \\
\hline Illiterate & $21(1.73)$ & \\
Literate & $1194(98.27)$ & \\
Total & 1215 & \\
Marital Status & & \\
\hline Unmarried & $177(14.21)$ & \\
Married & $1063(85.31)$ & \\
Widower/ & $6(0.48)$ & \\
Separated & & \\
Total & 1246 & \\
\hline Region & & \\
Bangalore & $1246(14.21)$ & \\
Delhi & $356(28.57)$ & \\
Kanpur & $388(31.14)$ & \\
Kolkata & $325(26.08)$ & \\
\hline Total & & \\
\hline
\end{tabular}

a few demographic questions (age, marital status, driving experience, education level and region). Finally, 1246 truck drivers (388 from the Kanpur region, 356 from the Delhi region, 325 from the Kolkata region and 177 from the Bangalore region) answered all or most of the questions. The overall response rate was $72 \%(=1246 / 1730)$. Nine truck drivers, who discontinued soon after joining, could not answer more than five questions (less than $25 \%$ of the 22 questions asked) and were excluded from the analysis.

Majority of truck drivers $(65 \%)$ were $30-50$ years old, with over 10 years of driving experience $(70 \%)$. Ninetyeight per cent were literate, $85 \%$ were married and all were men. Detailed demographic profiles of the truck drivers who participated in the study are given in table 1 .

\section{Knowledge and awareness}

Ninety-five per cent (1179) of 1245 truck drivers correctly answered that COVID-19 is communicable. Fifty per cent (623 of 1246) knew that the disease is treatable, and 66\% (817 of 1246) believed it might cause death. Fever as a symptom of the infection was known to $86 \%$ (1074 of 1246), followed by cough (66\%; 827 of 1246), difficulty 
in breathing $(53 \% ; 660$ of 1246$)$ and sore throat $(45 \%$; 558 of 1246). Only $43 \%$ (540 of 1246) of the truck drivers correctly answered all the questions regarding the signs and symptoms of COVID-19. Coming in contact with an infected person was the most cited route of infection, and $93 \%$ (1161 of 1246) of them were aware of it. On the contrary, only $32 \%$ (394 of 1246) correctly knew that it also spreads through respiratory droplets, while $39 \%$ (484 of 1246) incorrectly presumed that COVID-19 passes through the faecal-oral route. Truck drivers correctly answering all questions about the routes of transmission constituted only $8 \%$ (95) of 1246 drivers, $4 \%$ (55) were ignorant and $88 \%$ (1096) had partial knowledge.

Ninety per cent (1133) of the 1246 participants knew that elderly people were at higher risk of infection. Not many of them were aware of the other high-risk populations like young adults (quoted by 27\%; 333 of 1246), people with medical conditions (mentioned by 20\%; 243 of 1246), immunosuppressed people (said by 16\%; 243 of 1246) and those who have cancer, diabetes or chronic respiratory disease (cited by $14 \% ; 174$ of 1246). Forty-five per cent (563) of the 1246 truck drivers wrongly perceived children as prone to receive infection though they were not. None of the truck drivers could provide all correct answers to this question.

Sixty-five per cent (807) of 1242 truck drivers were aware that alcohol is not a panacea for COVID-19 infection. Twenty-seven per cent (333 of 1242) were hesitant to confirm or deny the statement. However, 8\% (102 of 1242) were confident that alcohol is a cure for the infection. Figure 1 shows the percentages of truck drivers having all-correct information about each knowledge question.

None of the knowledge factors except two, one probing if COVID-19 leads to death and the other probing its modes of transmission, were found to vary significantly across the age of the truck drivers. The proportion of drivers correctly answering that COVID-19 may cause death, which was $62 \%$ (135) of 217 younger drivers (below 30 years old) against $72 \%$ (155) of 216 older ones (above 50 years). Those between 30 and 50 years had $65 \%$ (527)

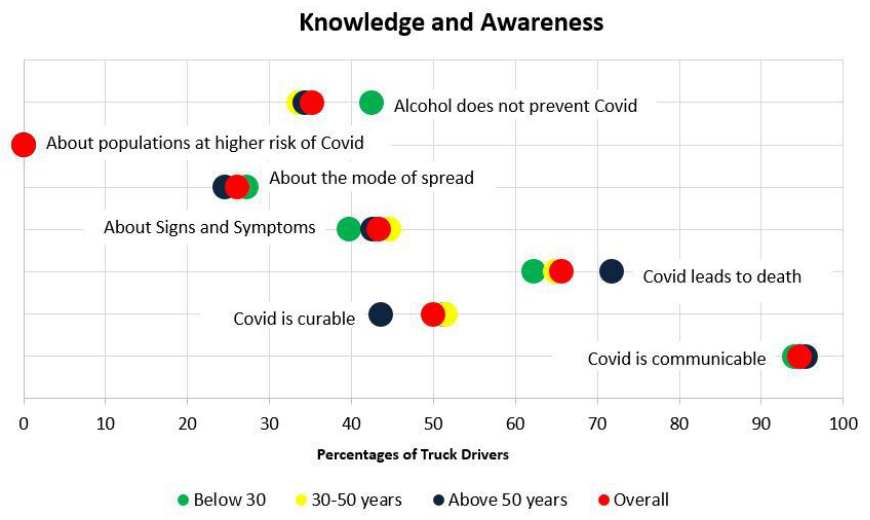

Figure 1 Percentage of drivers answering all the knowledge questions correctly and comparison of their percentages question-wise and age-wise (original). of 813 reporting the correct information. The difference is statistically significant ( $p$ value $=0.017$, Fisher's exact test). Fourty per cent (87) of the younger drivers correctly recognised respiratory droplets as a mode of spread of the infection. The proportions of drivers having correct information about the spread of infection through respiratory droplets in the $30-50$ years and above 50 years age groups were 29\% (237) and 32\% (70), respectively ( $p$ value $=0.008$, Fisher's exact test $)$.

Overall, the Knowledge Score from the total sample is estimated to be $46.6 \%$ (95\% CI $45.7 \%$ to $47.4 \%$ ): $45.2 \%$ among those below 30 years (95\% CI $43.1 \%$ to $47.4 \%$ ), $46.9 \%$ (95\% CI $45.8 \%$ to $48.0 \%$ ) among those $30-50$ years and $46.6 \%$ (95\% CI $44.7 \%$ to $48.5 \%$ ) among those over 50 years. The younger generation has the lowest average score. However, the difference in Knowledge Score across the age categories is not statistically significant ( $p$ value $=0.361$, ANOVA), however, it varies significantly across the regions ( $p$ value $=0.000$, ANOVA). Truck drivers staying in the Bangalore region were most knowledgeable, with an overall Knowledge Score of $55.4 \%$, followed by Delhi $(47.5 \%)$, Kolkata $(45 \%)$ and Kanpur (43\%). Figure 2 shows the region wise average Knowledge Scores at the corresponding 95\% CI.

\section{Sources of information}

The majority of the participants $(71 \%$ each in Kanpur and Delhi, 36\% in Bangalore, 24\% in Kolkata and 54\% in the total sample) reported their mobile phone as the primary information source. While the most frequented source of information was the mobile phone in Kanpur and Delhi, it was television in the Bangalore region (50\%) and social media and friends and families in the Kolkata region $(43 \%-44 \%)$. Radio and newspaper as the media of communication of COVID-19 messages did not have much penetration in the truck drivers' population, and it was same in all four regions. Table 2 details the sources of information across regions.

\section{Prevention practices}

Sixty-nine per cent (853) of 1241 truck drivers confirmed that they regularly clean their hands with an alcoholbased rub or soap and water, while $30 \%$ (371) do so only occasionally. Eighty-nine per cent (1103 of 1241) report wearing a mask whenever they go outside, although $11 \%$ (135) report wearing it only at times. Seventy per cent (865 of 1241) drivers always follow social distancing at public places and 29\% (356) are occasionally compliant. Seventy-two per cent (892 of 1233) disinfect their vehicles before use while $24 \%$ (302) do so sometimes. The prevalence of wearing a mask and disinfecting the vehicle before use differed significantly from one age group to another, with $\mathrm{p}$ values of 0.044 and 0.001 (Fisher's exact test), respectively. Significant or not, all four best practices are most prevalent in the 50 plus age group and least prevalent in the below 30 age group (figure 3 ).

All four standard prevention practices extensively and significantly vary across regions ( $p$ values $=0.000$ for each, 


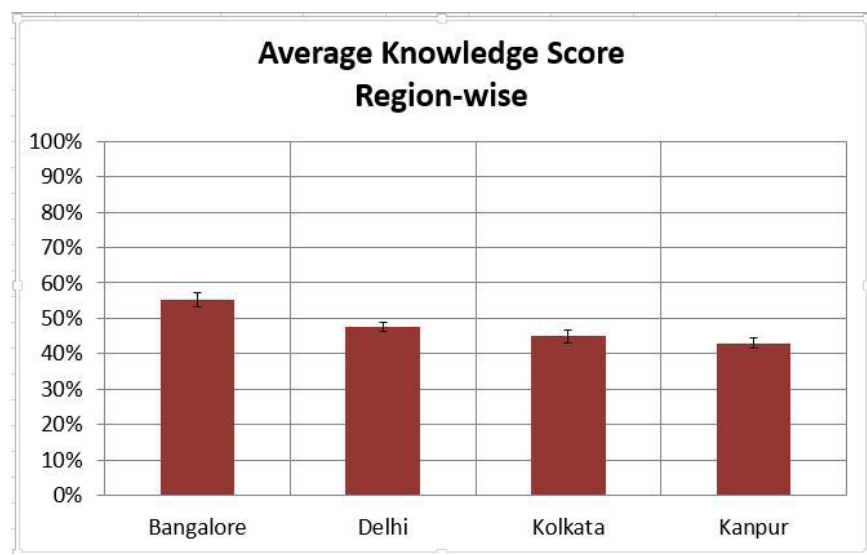

Figure 2 Region-wise average knowledge scores at the corresponding $95 \% \mathrm{Cl}$ (original).

Fisher's exact test), and the truck drivers belonging to the Kolkata region were least compliant. Only 17\% (56) of 325 follow the social distancing norm, $18 \%$ (57) wash their hands, $26 \%$ (86) disinfect the vehicle and $63 \%$ (206) wear a mask.

Truck drivers following standard prevention practices more frequently have higher average knowledge scores than those who do not (table 3). However, the statistical significance of the difference could be established only for the mask use. The average knowledge score among those who consistently wear a mask was $47 \%$; it was $42 \%$ among those who wear it sometimes and 29\% among those who wear it never ( $p$ value $=0.001$, ANOVA). The average knowledge score was $47 \%$ among those consistently following all four norms and $46 \%$ among those defaulting at least once ( $\mathrm{p}$ value $=0.698$, ANOVA).

\section{Worry regarding the disease}

Seventy-eight per cent (969) of 1246 truck drivers acknowledged that they worried a lot about COVID-19. Contrarily, $18 \%$ (221) of the truck drivers categorically said that they did not have such worries. Though the lowest proportion of worried drivers was found among the younger ones, no significant difference was observed between the age groups. However, the proportion of those worrying about the infection varies widely and significantly across the regions ( $p$ value $=0.000$, Fisher's exact test). Delhi has
Prevalence of Prevention Practices

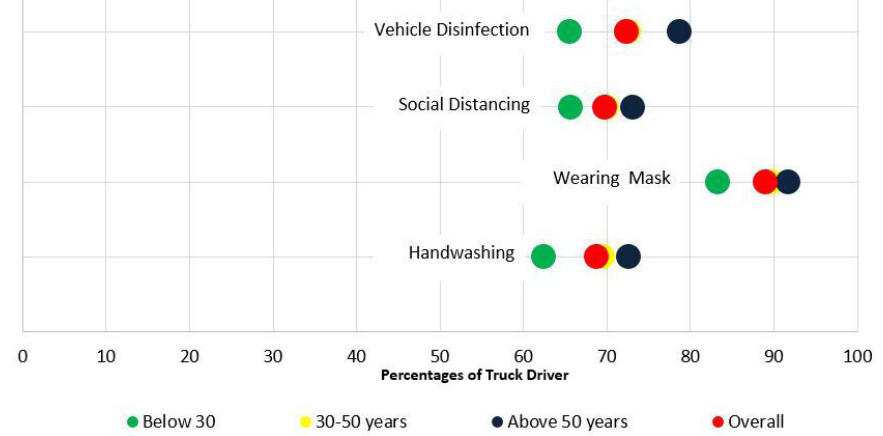

Figure 3 Age distribution of the prevalence of prevention practices (original).

the highest proportion of worried drivers, followed by Kolkata (86\%), Kanpur (70\%) and Bangalore (44\%).

\section{Financial challenges faced during lockdown}

Seventy-six per cent (935) of 1233 drivers reported being at home during the lockdown, 14\% (167) drivers reported being stuck in another city, while the remaining $11 \%$ (131) drivers were at the transporter's office, either stuck on the highway or at some other place. Ninety-three per cent (1144) of 1233 truck drivers said that they were getting food regularly during the lockdown, while the remaining $7 \%$ (89) drivers said that they were either able to get food only sometimes $(6 \% ; 72)$ or not at all $(1 \% ; 17)$. Majority $(74 \% ; 916)$ of 1233 drivers were able to access health services easily during the lockdown, $8 \%$ (93) were able to do so only sometimes and $18 \%$ (224) drivers were not able to do so at all.

Over half the drivers, $(55 \%$; 674 of 1233$)$ received only part payment for their work, while almost $6 \%$ (72) drivers did not receive remuneration of any kind during this period. Under $1 \%$ drivers owned their own vehicle and, thus, were not eligible to receive payments. Only $39 \%$ (480) drivers received full payment. The proportion of drivers receiving payment in full varied significantly across age groups ( $p$ value $=0.005$, Fisher's exact test). Over half the truck drivers $(50 . \%)$ who received full payment were

Table 2 Numbers and percentages of drivers in each region citing the medium as a source of information about COVID-19 (original)

\begin{tabular}{lllllll}
\hline & Bangalore (\%) & Delhi (\%) & Kanpur (\%) & Kolkata (\%) & Total & P value \\
\hline Mobile & $64(36.16)$ & $252(70.79)$ & $276(71.13)$ & $78(24)$ & $670(53.77)$ & $<0.001^{\star \star}$ \\
Television & $89(50.28)$ & $98(27.53)$ & $119(30.67)$ & $60(18.46)$ & $366(29.37)$ & $<0.001^{\star \star}$ \\
Social Media & $20(11.3)$ & $84(23.6)$ & $65(16.75)$ & $142(43.69)$ & $311(24.96)$ & $<0.001^{\star \star}$ \\
Family and Friends & $8(4.52)$ & $1(0.28)$ & $15(3.87)$ & $141(43.38)$ & $165(13.24)$ & $<0.001^{\star \star}$ \\
Radio & $18(10.17)$ & $14(3.93)$ & $37(9.54)$ & $0(0)$ & $69(5.54)$ & $<0.001^{\star \star}$ \\
News Paper & $1(0.56)$ & $5(1.4)$ & $38(9.79)$ & $18(5.54)$ & $62(4.98)$ & $<0.001^{\star \star}$ \\
Other & $23(12.99)$ & $1(0.28)$ & $5(1.29)$ & $0(0)$ & $29(2.33)$ & $<0.001^{\star}$ \\
Total & 177 & 356 & 388 & 325 & 1246 & \\
\hline
\end{tabular}


Table 3 Knowledge score (mean $\pm S D$ ) of the truck drivers vis-à-vis their prevention practices (original)

\begin{tabular}{llllll}
\hline & Hand wash & Mask use & Social distancing & Vehicle disinfection & All four practices \\
\hline Always & $47 \% \pm 15 \%$ & $47 \% \pm 15 \%$ & $47 \% \pm 15 \%$ & $47 \% \pm 15 \%$ & $47 \% \pm 15 \%$ \\
Sometimes & $46 \% \pm 16 \%$ & $42 \% \pm 16 \%$ & $46 \% \pm 16 \%$ & $45 \% \pm 16 \%$ & $46 \% \pm 16 \%$ \\
Never & $45 \% \pm 15 \%$ & $29 \% \pm 29 \%$ & $42 \% \pm 20 \%$ & $44 \% \pm 13 \%$ & 0.698 \\
P values & 0.526 & $0.001^{*}$ & 0.370 & 0.150 & 0 \\
\hline
\end{tabular}

in the under 30 age group, followed by those in the $30-50$ $(37 \%)$ and over $50(36 \%)$ age groups.

The proportion of drivers varied significantly across region for all these challenging scenarios $(p$ value $=0.000$, Fisher's exact test). Kanpur fared the best among all the regions, with the highest proportion of drivers at home (91\%; 354 of 387 ), able to source food regularly (99\%; 384 of 387$)$ and able to access health services (99\%; 384 of 387). This was followed by Bangalore where $87 \%$ (152 of 175) drivers were at home during the lockdown, $99 \%$ (173 of 175) were able to source food and 91\% (159 of $175)$ were able to access healthcare when required. Delhi had $73 \%$ (253 of 346) drivers at home during the lockdown, $97 \%$ (336 of 346) with regular access to food and $63 \%$ (218 of 346) able to access healthcare services easily. Drivers in Kolkata fared the worst in all these situations as only $54 \%$ (176 of 325 ) were at home during the lockdown, $77 \%$ (251 of 325) able to procure food regularly and only $48 \%$ (155 of 325 ) able to access health services.

\section{DISCUSSION}

\section{Key results}

The majority of drivers answered knowledge-related questions, correctly, apart from questions about curability, all signs and symptoms, all routes of transmission, all highrisk populations and alcohol as treatment for the disease. Mobile phones were the most reported primary source of information across the sample with some differences across regions. Lion's share of the truck drivers reported following the listed practices regularly and worrying about the disease. Less than two-fifths of the drivers received full pay during this period, though most did not face dire situations, reportedly being at home, able to source food and access health services regularly.

\section{Knowledge and awareness}

Although most truck drivers were aware that people-topeople infection is the obvious mode of transmission of COVID-19, less than a third knew about respiratory droplets being another significant mode of transmission; a combined proportion, almost double that reported in the general Indian population. ${ }^{24}$ Furthermore, in our study, over a third presumed incorrectly that the foecaloral route was a method of transmission. Overall, only $8 \%$ of the drivers were aware of all the correct routes of COVID-19 transmission.

Additionally, none of the drivers was able to correctly identify all the at-risk populations. While the majority knew about the elderly being at risk, under 30\% were aware regarding young adults, those with comorbidities or chronic medical conditions and those with low immunity. Infact, $45 \%$ truck drivers even incorrectly mentioned that children are a high-risk age group. Incidentally, the proportion of drivers who answered that drinking alcohol does not prevent COVID-19 was similar across our study and referenced literature. ${ }^{23}$

In our study, only half the truck drivers were aware that COVID-19 is treatable. While, fever as a symptom was known to most, just around half the truck drivers knew that trouble breathing and sore throat were also major signs and symptoms pointing to the disease. Overall, less than half the participants correctly answered the questions regarding all the signs and symptoms. Contrarily, a study of the Indian rural community reports that over $85 \%$ of participants, double the proportion of correct drivers in our sample, were aware of the signs and symptoms. ${ }^{22}$

It is important to note, however, that while a general Indian study ${ }^{20}$ and the rural Indian study ${ }^{22}$ report higher awareness and knowledge among their study participants, they have a higher proportion of younger participants. The age difference between the sample of participants among the previous two studies, and the sample of participants in the study of rural out patients ${ }^{21}$ and our study, becomes especially important as the latter two report a higher proportion of correct answers for questions related to COVID-19, leading to death and its modes of transmission given by drivers in the over 50 age group. Thus, our study demonstrates considerable need to target COVID-19 awareness and knowledge programmes at the drivers in the under 50 age groups, in line with a study of the general population in India, China and Pakistan, where those in the 30 and under age groups were found to be less knowledgable and less aware. ${ }^{41}$

Moreover, our results indicate that the distribution of information and awareness regarding the disease is not uniform pan-India. The significant variation in the Knowledge Score across regions demonstrates that truck drivers in Kanpur were the most ill-informed.

\section{Prevention practices}

The majority of drivers in our sample reported following prevention practices regularly, while only a third of the drivers reported doing so regularly. These figures are in line with a study of out patients in rural north Indian hospitals, higher only in terms of compliance to regular mask usage and lower only in terms of frequency of hand 
hygiene. ${ }^{21}$ On the other hand, proportions of compliance with prevention practices in our study are less in number compared with a similar study of the general Indian population, which reported that $97.6 \%$ of the 383 men they surveyed washed their hands regularly and $95.2 \%$ practised social distancing. ${ }^{20}$ These results are a possible reflection of the lower risk averseness in the younger truck drivers. Furthermore, truck drivers in Kolkata were the least compliant in terms of the four prevention practices, and significantly so. Infact, while a little less than two-thirds of these drivers do report wearing masks, a very low proportion pay heed to the rest of the practices.

In our study, we find that truck drivers with higher average knowledge scores did report following standard prevention practices more frequently. These results were found to be significant for those who had high knowledge scores and reported wearing masks. Overall, knowledge and awareness in the general population of India, China and Pakistan regarding COVID-19 have been shown to be significantly correlated with their prevention practices. ${ }^{41}$

\section{Sources of information}

The mobile phone was reported as the primary source of information for the majority of drivers in our study, with radio and newspaper getting the least traction. Contrarily, radio, television and newspaper were the most relied on sources of information in rural India. ${ }^{21} 22$ These disparities seem to be in large part a function of availability and accessibility of different information sources across different infrastructure development and literacy levels as well as a result of the mobility offered by mobile phones, which may lead to their being given special preference by the nomadic population of truck drivers.

Previous literature regarding prevention practices and awareness regarding COVID-19 on the global platform have focused on topics such as perspectives, awareness levels and barriers reported by health professionals in implementing prevention strategies, ${ }^{25-28} 42$ and the attitudes, knowledge levels and practices followed among certain populations. ${ }^{25}$ 29-34 43 Literature focused on the Indian population en masse highlights the need for knowledge and awareness programmes regarding COVID-19,,$^{20-24} 44$ and prevention practices currently being followed. ${ }^{20} 2123$ Although the disproportionately adverse socioeconomic impact of the pandemic and the subsequent lockdown on vulnerable migrant populations has been documented in the developed ${ }^{45} 46$ and developing countries, ${ }^{47}$ including India, ${ }^{49}$ few studies have focused on the truck driver population, in particular. On the other hand, global studies regarding the awareness and knowledge levels of truck drivers have primarily focused on sexual health. ${ }^{35} 36$

\section{Strengths and limitations}

A seminal strength of this study is the large sample of truck drivers surveyed, to fulfil an important literature gap and provide information that can be used to plan much needed awareness campaigns and programmes targeted at this unique mobile population, especially in the face of any further pandemic situation that may arise. However, the self-reported nature of the prevention practices being followed may lead to their overestimation and constitute a limitation, as would the fact that the drivers included are those already accessing services from the organisation through the DCP.

Furthermore, the use of the telephonic survey methodology limits the results of this study to those who could be reached via mobile cellular devices, as physical interviews were not possible during the pandemic. While the study questionnaire was designed in English, it was translated into Hindi in which it was administered, without any backtranslating. Moreover, the respondents were not anonymised from the interviewers, which may have also led to more socially desirable responses, although participants were made fully aware that their responses would be anonymised from the fleet owners as well as hospital staff delivering eyecare services. We also do not present our results in relation to any established theories or models of behaviour as this study was designed as an exploratory and descriptive study. However, using those to design, the questionnaire could have guided us to plan interventions with more impact.

Despite these limitations, this study has generalisable results as truck drivers across multiple regions of the country were included in the analysis and the study period being immediately after the national lockdown decreased the recall bias that would otherwise have persisted. Truck drivers in India have been shown to have similar lifestyles and comorbidities as those in both developed and developing countries, especially when it comes to smoking and alcohol usage, prevalence of hypertension and diabetes, obesity or other cardiovascular risk factors,,${ }^{11250-52}$ all of which are also risk factors for severe COVID-19 disease. Therefore, results from this study may be generalisable to those populations as well.

\section{CONCLUSION}

Our study demonstrates that awareness regarding COVID-19 is still low among this vulnerable population (both in terms of mobile jobs as well as high risk of infection due to comorbidities). Consequently, it can be understood that awareness regarding other diseases, not as apparant and widespread as this, may be still lower. Integrating awareness activities with other initiatives and programmes currently being run by the government (like HIV and vaccinations) and provisioning social security and/or insurance through fleet owners/ cooperative societies that may be useful not only for the present COVID-19 pandemic, which is still not over, but also for similar situations that may limit availability of assignments, might be important safeguards, ${ }^{49}$ especially as all truck drivers are not trained to do alternative jobs. Moreover, information dissemination through mobile phones, the primary source of information for this mobile population may help future health promotion activities. 
Acknowledgements We gratefully acknowledge the EICHER Group, India, for support in running the Driver Care Program. We also thank Mr Rakesh Kumar (Program Coordinator), Mr Mukesh Kumar (Junior Coordinator), Mr Bhoopender Kumar (Junior Coordinator) and Mr Vikram Singh (Junior Coordinator) from Dr Shroff's Charity Eye Hospital, New Delhi, Mr Vikas Kumar (Program In-charge), Mr Shubham Sahu (Optomestrist), Mr Rohit Singh (Coordinator), Mr Shiva Yadav (Field Officer) and Mr Pradeep Singh (Driver) from Dr Jawahar Lal Rohtagi Eye Hospital, Kanpur, Mr BG Nataraja (Program In-charge), Mr Nagaraja KM (Coordinator), Mr Basavaraju (Optomestrist), Mr Santhosh (Technician) and Mr Shankar C (Driver) from Vittala International Institute of Ophthalmology, Bengaluru, and Mr Tuhin Saini (Program In-charge), Mr Samir Tudu (VT), Mr Soumik Kanji (Coordinator and Mobilizer) and Mr Binod Hembram (Junior Coordinator and Optical Fitter) from Susrut Eye Hospital And Research Centre, Kolkata, for their hardwork and dedication in making this research endeavour possible.

Contributors IS was involved in planning, writing of the manuscript and making revisions. AC was involved in planning, concept and design, conduct and acquisition of data. AM was involved in data analysis and interpretation. SS was involved in planning, concept and design, data interpretation and reviewing the manuscript and will act as guarantor of this manuscript.

Funding The authors have not declared a specific grant for this research from any funding agency in the public, commercial or not-for-profit sectors.

Competing interests None declared.

Patient and public involvement Patients and/or the public were involved in the design, or conduct, or reporting, or dissemination plans of this research. Refer to the Methods section for further details.

\section{Patient consent for publication Not applicable.}

Ethics approval This study involves human participants and was approved by the Institutional Review Board of Dr. Shroff's Charity Eye Hospital (IRB/2020/APR/53) and adheres to the tenets in the Declaration of Helsinki. Participants gave informed consent to participate in the study before taking part.

Provenance and peer review Not commissioned; externally peer reviewed.

Data availability statement All data relevant to the study are included in the article or uploaded as supplementary information.

Open access This is an open access article distributed in accordance with the Creative Commons Attribution Non Commercial (CC BY-NC 4.0) license, which permits others to distribute, remix, adapt, build upon this work non-commercially, and license their derivative works on different terms, provided the original work is properly cited, appropriate credit is given, any changes made indicated, and the use is non-commercial. See: http://creativecommons.org/licenses/by-nc/4.0/.

\section{ORCID IDs}

Ishaana Sood http://orcid.org/0000-0003-4907-2956

Shalinder Sabherwal http://orcid.org/0000-0001-7687-0748

\section{REFERENCES}

1 World Health Organization. Timeline: WHO's COVID-19 response. Available: https://www.who.int/emergencies/diseases/novelcoronavirus-2019/interactive-timeline/\# event-3 [Accessed 21 Mar 2021].

2 Bureau of Immigration. Advisory: travel and visa restrictions related to COVID-19. Available: https://boi.gov.in/content/advisory-traveland-visa-restrictions-related-covid-19-1 [Accessed 21 Mar 2021].

3 Ministry of Foreign Affairs, Singapore. COVID-19 travel restrictions. Available: https://www.mfa.gov.sg/Services/Singapore-Citizens/ COVID-19-Travel-Restrictions [Accessed 21 Mar 2021].

4 Centers for Disease Control and Prevention. COVID-19 travel recommendations by destination. Available: https://www.cdc.gov/ coronavirus/2019-ncov/travelers/map-and-travel-notices.html [Accessed 21 Mar 2021].

5 GOV.UK. Entering the UK. Available: https://www.gov.uk/uk-bordercontrol [Accessed 21 Mar 2021].

6 National Aids Control Organization. Targeted interventions for TRUCKERS: operational guidelines. Available: http://naco.gov.in/ sites/default/files/26\%2C\%20Targeted\%20Interventions\%20for\% 20Truckers\%20-\%20Operational\%20Guidelines.pdf [Accessed 21 Mar 2021]

7 KPMG. Skill gaps in the Indian logistics sector: a white paper. Available: http://www.in.kpmg.com/pdf/logistics.pdf [Accessed 21 Mar 2021].
8 Hsiang S, Allen D, Annan-Phan S, et al. The effect of large-scale anti-contagion policies on the COVID-19 pandemic. Nature 2020;584:262-7.

9 Aklilu TM, Abebe W, Worku A. The impact of COVID-19 on care seeking behavior of patients at tertiary care follow-up clinics: a cross-sectional telephone survey. Addis Ababa, Ethiopia. medRxiv2020:2020.11.25.20236224.

10 Tian S, Li D, Lou J. Health-seeking behavior of patients with COVID-19 infection. Research Square, 2020.

11 Udayar SE, Konduru RK, Kumar BAP. Study of cardiovascular risk factors among transport drivers in rural area of Andhra Pradesh. IJRHS 2014;2:420-6.

12 Sabherwal S, Sood I, Chinnakaran A. Hypertension in Indian Truckers: the need for comprehensive service provision to this mobile population (2017-18). JOHE 2020;9:85-90.

13 Sabherwal S, Sood I, Chinnakaran A. The prevalence of refractive errors and spectacle uptake in truckers: a North Indian crosssectional study. J Clin Ophthalmol Res 2020;8:51-5.

14 Lalla-Edward ST, Matthew P, Hankins CA, et al. Healthcare for truck drivers: assessing accessibility and appropriateness of South African roadside wellness centres. J Transp Health 2018;8:63-72.

15 Sharma V, Saggurti N, Bharat S. Health care coverage among longdistance truckers in India: an evaluation based on the Tanahashi model. Hiv Aids 2015;7:83-94.

16 Sabherwal S, Chinnakaran A, Singh BP. Barriers to uptake of Eyecare services amongst commercial Truck-Drivers in North India: a crosssectional survey. Indian J Public Health Res Dev 2020;11:853-9.

17 Chanda S, Randhawa S, Bambrah HS, et al. Bridging the gaps in health service delivery for truck drivers of India through mobile medical units. Indian J Occup Environ Med 2020;24:84-90.

18 REUTERS. India's truckers in crisis: Police checks, no food and fears of coronavirus. Available: https://www.reuters.com/article/us-healthcoronavirus-india-freight/indias-truckers-in-crisis-police-checks-nofood-and-fears-of-coronavirus-idUSKCN2260VE [Accessed 21 Mar 2021].

19 The New York Times. Modi orders 3-week total Lockdown for all 1.3 billion Indians. Available: https://www.nytimes.com/2020/03/ 24/world/asia/india-coronavirus-lockdown.html [Accessed 14 Aug 2021].

20 Kartheek AS, Gara KH, Vanamali DR. Knowledge, attitude and practices towards COVID-19 among Indian residents during the pandemic: a cross-sectional online survey. J Dr NTR Univ Health Sci 2020;9:107-15.

21 Gupta P, Gupta A, Dixit S, et al. Knowledge, attitude, and practices regarding COVID-19: a cross-sectional study among rural population in a northern Indian district. J Family Med Prim Care 2020;9:4769-73.

22 Ranjan R, Ranjan GK. Knowledge regarding prevention of novel coronavirus (COVID-19): an electronic cross-sectional survey among selected rural community. Int J Trend Res 2020;4:422-6.

23 Tomar BS, Singh P, Suman S. Indian community's Knowledge, Attitude \& Practice towards COVID-19. medRxiv2020:2020.05.05.20092122.

24 Pandey S, Gupta A, Bhansali R. Corona Virus (COVID-19) Awareness Assessment - A Survey Study amongst the Indian Population. J Clin Med Res 2020;2:1-11.

25 Saqlain M, Munir MM, Rehman SU, et al. Knowledge, attitude, practice and perceived barriers among healthcare workers regarding COVID-19: a cross-sectional survey from Pakistan. J Hosp Infect 2020;105:419-23.

26 Basu S, Rustagi R, Sharma P, et al. Perceived awareness, practices and perspectives on COVID-19 management among medical doctors in India: a repeated cross-sectional study. Popul Med 2020;2:1-6.

27 Ssebuufu R, Sikakulya FK, Mambo SB, et al. Knowledge, attitude, and self-reported practice toward measures for prevention of the spread of COVID-19 among Ugandans: a nationwide online crosssectional survey. Front Public Health 2020;8:890.

28 Singh Gambhir R, Singh Dhaliwal J, Aggarwal A, et al. Covid-19: a survey on knowledge, awareness and hygiene practices among dental health professionals in an Indian scenario. Rocz Panstw Zakl Hig 2020;71:223-9.

29 Lee RWK, Loy SL, Yang L, et al. Attitudes and precaution practices towards COVID-19 among pregnant women in Singapore: a crosssectional survey. BMC Pregnancy Childbirth 2020;20:675.

30 Pal R, Yadav U, Grover S, et al. Knowledge, attitudes and practices towards COVID-19 among young adults with type 1 diabetes mellitus amid the nationwide lockdown in India: a cross-sectional survey. Diabetes Res Clin Pract 2020;166:108344.

31 Okello G, Izudi J, Teguzirigwa S, et al. Findings of a cross-sectional survey on knowledge, attitudes, and practices about COVID-19 in Uganda: implications for public health prevention and control measures. Biomed Res Int 2020;2020:1-8. 
32 Ahmed N, Shakoor M, Vohra F, et al. Knowledge, awareness and practice of health care professionals amid SARS-CoV-2, corona virus disease outbreak. Pak J Med Sci 2020;36:S49-56.

33 Kassa AM, Mekonen AM, Yesuf KA, et al. Knowledge level and factors influencing prevention of COVID-19 pandemic among residents of Dessie and Kombolcha City administrations, north-east Ethiopia: a population-based cross-sectional study. BMJ Open 2020;10:e044202.

34 Dewau R, Mekonnen TC, Tadesse SE, et al. Knowledge and practice of clients on preventive measures of COVID-19 pandemic among governmental health facilities in South Wollo, Ethiopia: a facilitybased cross-sectional study. PLoS One 2021;16:e0247639.

35 Ishtiaq R, Asif A, Jamil AR, et al. Knowledge and attitude about sexually transmitted infections amongst truck drivers in southern Punjab, Pakistan. Cureus 2017:9:e1118.

36 Matovu JKB, Ssebadduka NB. Knowledge, attitudes \& barriers to condom use among female sex workers and truck drivers in Uganda: a mixed-methods study. Afr Health Sci 2013;13:1027-33.

37 Versteeg K, Amoli T, Cao M, et al. Mixed-method analysis of truck driver health knowledge using an online forum. Saf Sci 2018;102:51-9.

38 Das K, Dasgupta A, Naskar NN, et al. How aware are our truck drivers regarding prevention of road traffic accidents? A crosssectional study in Dankuni area, Hooghly. Int J Community Med Public Health 2020;7:1084-8.

39 Gnimbar PODA G, Sondet SANON G. Hiv/Aids knowledge, attitudes and practices among truck drivers in Burkina Faso. JCRHAP 2015;2:18-27.

40 Centers for Disease Control and Prevention. Long-Haul truck drivers. Available: https://www.cdc.gov/coronavirus/2019-ncov/community/ organizations/long-haul-trucking-employees.html [Accessed 14 Aug 2021]

41 Qalati SA, Ostic D, Fan M, et al. The general public knowledge, attitude, and practices regarding COVID-19 during the Lockdown in Asian developing countries. Int Q Community Health Educ 2021:0272684X2110049.

42 Mersha A, Shibiru S, Girma M, et al. Perceived barriers to the practice of preventive measures for COVID-19 pandemic among health professionals in public health facilities of the Gamo zone, southern Ethiopia: a phenomenological study. BMC Public Health 2021;21:199.

43 Muluneh Kassa A, Gebre Bogale G, Mekonen AM. Level of perceived attitude and practice and associated factors towards the prevention of the COVID-19 epidemic among residents of Dessie and Kombolcha town administrations: a population-based survey. Res Rep Trop Med 2020;11:129-39.

44 Kaushik M, Agarwal D, Gupta AK. Cross-Sectional study on the role of public awareness in preventing the spread of COVID-19 outbreak in India. Postgrad Med J 2021;97:777-81.

45 Tuyisenge G, Goldenberg SM. COVID-19, structural racism, and migrant health in Canada. Lancet 2021;397:650-2.

46 Clark E, Fredricks K, Woc-Colburn L, et al. Disproportionate impact of the COVID-19 pandemic on immigrant communities in the United States. PLoS Negl Trop Dis 2020;14:e0008484.

47 Bukuluki P, Mwenyango H, Katongole SP, et al. The socio-economic and psychosocial impact of Covid-19 pandemic on urban refugees in Uganda. Soc Sci Humanit Open 2020;2:100045.

48 Mukumbang FC, Ambe AN, Adebiyi BO. Unspoken inequality: how COVID-19 has exacerbated existing vulnerabilities of asylumseekers, refugees, and undocumented migrants in South Africa. Int $J$ Equity Health 2020;19:141.

49 Khanna A. Impact of migration of labour force due to global COVID-19 pandemic with reference to India. $J$ Health Manag 2020:22:181-91.

50 Krishnamoorthy Y, Sarveswaran G, Sakthivel M. Prevalence of hypertension among professional drivers: evidence from 2000 to 2017-A systematic review and meta-analysis. J Postgrad Med 2020;66:81-9.

51 Sangaleti CT, Trincaus MR, Baratieri T, et al. Prevalence of cardiovascular risk factors among truck drivers in the South of Brazil. BMC Public Health 2014;14:1063.

52 Sieber WK, Robinson CF, Birdsey J, et al. Obesity and other risk factors: the National survey of U.S. long-haul truck driver health and injury. Am J Ind Med 2014;57:615-26. 